\title{
Impacts of Agricultural Management Practices on the Risk of Nitrogen and Phosphorus Losses at Catchment Scales by Using GIS and Index Models
}

\author{
Ping Zhang ${ }^{1, *}$, Liang $\mathrm{He}^{2}$, Tao Zhang ${ }^{3}$ and Peishu Huo ${ }^{4}$ \\ ${ }^{1}$ School of Environmental and Chemical Engineering, Xi an Polytechnic University, Xi an 710048, China \\ ${ }^{2} X i^{\prime} a n$ Environmental Monitoring Station, Xi an 710054, China \\ ${ }^{3}$ Institute of Grassland Science, Northeast Normal University, Key Laboratory of Vegetation Science, Ministry of Educa- \\ tion, Changchun 130024, China \\ ${ }^{4}$ School of Environment, Tsinghua University, Beijing 100084, China
}

\begin{abstract}
The unreasonable agricultural management measure is the main cause of the risk of nitrogen and phosphorus losses. The objective of this paper was to evaluate the impacts of agricultural management practices on the risk of nitrogen and phosphorus losses at catchment scales based on GIS and integrated index models. The results showed that $93.1 \%$ of the catchment was no risk and low risk area, while $6.9 \%$ for medium and high risk of nitrogen and phosphorus losses. Spatial analysis of risk index indicated that different agricultural management practices lead to number and proportion of grids are different. At very high risk area, about 599 of grid number is only for the actual management practice, accounting for $0.22 \%$ of the total, while at very low risk area, 165884.00 and $60.51 \%$ for river buffer zone respectively. Control effect of different agricultural management practices for risk of nitrogen and phosphorus losses is better, which very low and low risk areas of based fertilizer applied deeply and buffer zone construction accounted for $98 \%$ and $95.6 \%$, and the control effect sorted as follows: base fertilizer applied deeply> construction of river buffer zone $>$ reduced nitrogen application> reduced phosphorus application.
\end{abstract}

Keywords: Integrated index models, agricultural management practices, nitrogen and phosphorus losses, risk assessment

\section{INTRODUCTION}

Non-point source pollution caused by nitrogen and phosphorus losses is the main cause of eutrophication in water bodies. Identification of the critical source areas (CSA) of nutrient loss is essential to improve management efficiency, reduce cost and targeted regulation of control strategies [1$3]$.

Nitrogen and phosphorus losses process is a complex process of non-point source pollution, which including topography, soil, climate, surface runoff, land use types, planting management, nutrient transport characteristics and varies both temporally and spatially [4-6]. Considered separately, however, nitrogen or phosphorus losses in any one party has not been sufficient to control eutrophication problem brought by the nutrient loss, and due to the differences between the biological, chemical and migration process for nitrogen and phosphorus in the soil, single targeted governance does not achieve the overall goal of improving water quality [7-10]. Therefore, it is necessary to conduct a comprehensive

*Address correspondence to this author at the School of Environmental and Chemical Engineering, Xi' an Polytechnic University, Xi an 710048, China; Tel: 18717361781; E-mail: miracle1891@126.com assessment of nitrogen and phosphorus losses risk, and to develop an integrated management control strategies. But, only a few studies to carry out integrated index evaluation of nitrogen and phosphorus losses provide a reference for the watershed management.

The objective of this paper was to evaluate the risk of nutrient losses under different agricultural management practices by using GIS and phosphorus and nitrogen index models. A case study at Dongzhuang catchment, northeast Beijing of China is presented. The results will provide a reasonable basis to control strategy of nitrogen and phosphorus losses for the catchment scales.

\section{THE STUDY AREA}

The case study and analysis presented here is focused on the $6.9 \mathrm{~km}^{2}$ Dongzhuang catchment, located at northeast of Miyun county, Beijing of China (Fig. 1), which approximately $71.21 \%$ is forest land and the remaining parts are agricultural land, orchard, inhabited areas and water bodies, with an average annual rainfall of $660 \mathrm{~mm}$, an average annual evaporation of $1783.2 \mathrm{~mm}$, the average annual temperature is approximately $10.9^{\circ}$ Cand altitude from 220 to $640 \mathrm{~m}$ over the study area. Landscape dominated by hills and low 


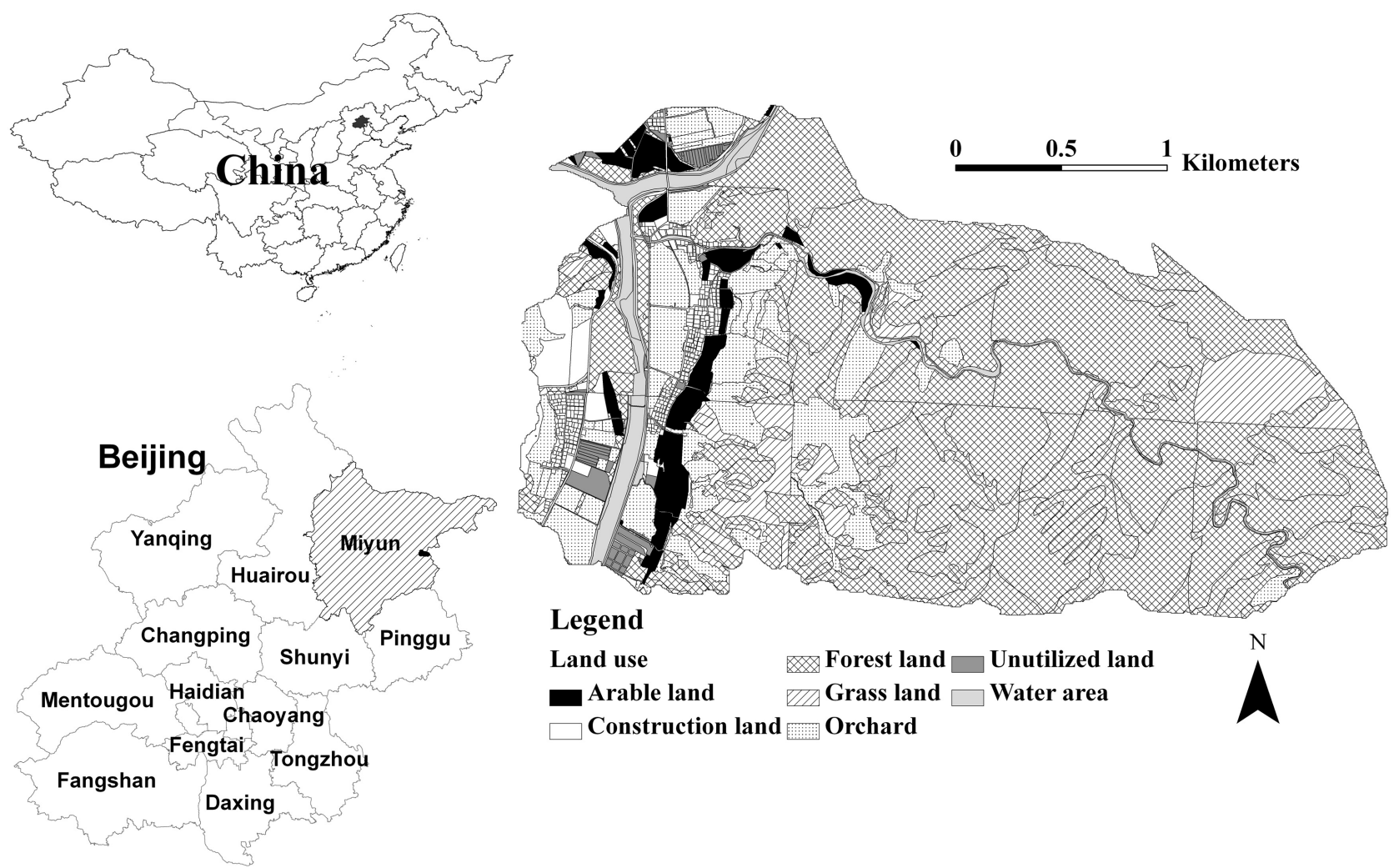

Fig. (1). Location of Dongzhuang Catchment, Northeast Miyun County, Beijing of China.

mountains, soil texture is mainly light loam. Natural vegetation is mainly coniferous forest, and some shrubs. This study area of land is given priority to with agriculture, which is mainly chestnut, apricot, apple, walnut, pear, etc. Field crops are mainly wheat, corn, vegetables and so on Dongzhuang catchment belongs to upstream of the Miyun Reservoir, it is very important to protect the surface drinking water sources by integrating control measures of nitrogen and phosphorus losses within the catchment risk assessment.

\section{MATERIALS AND METHODS}

\subsection{Soil Erosion Index}

Soil erosion is important nonpoint source pollution, as well as the significant carrier of pollutants migration, and the USLE approach was adopted to calculate the risk of soil erosion in this paper.

\subsubsection{Rainfall and Runoff Factors}

$R=\sum_{i=1}^{12}\left(1.735 \times 10^{\left(1.5 \log \frac{P_{i}^{2}}{p}-0.8188\right)}\right)$

Where, $R$ is rainfall and runoff factors $\left(100 \mathrm{ft} \cdot \mathrm{t} \cdot \mathrm{in} \cdot \mathrm{ac}^{-}\right.$ ${ }^{1} \cdot \mathrm{h}^{-1} \cdot \mathrm{a}^{-1)}, P$ are the average annual precipitation $(\mathrm{mm}), P_{i}$ monthly precipitation $(\mathrm{mm})$.

\subsubsection{Soil Erosion Impact Factor}

$\mathrm{K}=\{0.2+0.3 \exp [-0.0256 \mathrm{Sa}(1-\mathrm{Si} / 100)]\}$

$(\mathrm{Si} /(\mathrm{Cl}+\mathrm{Si}))^{\wedge}(0.3)[1-(0.25 \mathrm{C}) /(\mathrm{C}+\exp$

$(3.72-2.95 \mathrm{C}))][1-(0.7 \mathrm{Sn}) /(\mathrm{Sn}+\exp$

$$
(-5.51+22.9 \mathrm{Sn}))]
$$

Where, $S_{n}=1-S_{a} / 100, S_{a}$ is sand content (\%), $S_{i}$ is silt content $(\%), C l$ is clay content $(\%), C$ is organic matter content $(\%)$.

\subsubsection{Slope Length Factor}

$L_{\star i, j}=\frac{\left(A_{(i, j)}+D^{2}\right)^{m+1}-A_{(i, j)}^{m+1}}{X_{(i, j)}^{m} \times D^{m+2} \times 22.13^{m}}$

Where, $L_{(i, j)}$ is the coordinates $(i, j)$ slope length factor grid cell, $A_{(i, j)}$ is the coordinates $(i, j)$ grid cells uphill catchment area; $D$ is $x(i, j)$ for the contour length of the line through the grid cells, size grid cell.

$$
\begin{aligned}
& X_{(i, j)}=\left|\sin \alpha_{(i, j)}+\right| \cos \alpha_{(i, j)}|| \\
& \beta=\frac{\sin \theta / 0.0896}{3 \times(\sin \theta)^{0.8}+0.56}
\end{aligned}
$$




$$
m=\frac{\beta}{1+\beta}
$$

Where, $\alpha$ is the terrain slope, $\theta$ is the slope, $m$ is the slope length index.

$$
S=-1.5+\frac{17}{1+e^{2.3-6.1 \times \sin \theta}}
$$

Where, $S$ is the slope factor.

\subsection{Phosphorus Index}

Calculation of the phosphorus index is as follows [11]:

$$
P_{\text {index }}=\sum_{i=1}^{n}\left(S_{i} \cdot W_{i}\right) \times \sum_{j=1}^{n}\left(T_{j} \cdot W_{j}\right)
$$

Where $P_{\text {index }}$ is phosphorus index, $S_{i}$ is the source factor rating and $W_{i}$ is the weighting factor, $T_{j}$ is the transport factor rating and $W_{j} i s$ the weighting factor.

\subsection{Nitrogen Index}

Calculation of the nitrogen index is as follows [12-14].:

$$
N_{\text {index }}=\sum_{i=1}^{n}\left(S_{i} \cdot W_{i}\right) \times \sum_{j=1}^{n}\left(T_{j} \cdot W_{j}\right)
$$

Where $N_{\text {index }}$ is nitrogen index, $S_{i}$ is the source factor rating and $W_{i}$ is the weighting factor, $T_{j}$ is the transport factor rating and $W_{j} i s$ the weighting factor.

\subsection{Nitrogen and Phosphorus Integrated Index}

The risk of phosphorus and nitrogen index was averaged into one integrated index as following.

$$
I_{\text {Integrated }}=\left(I_{P}+I_{N}\right) / 2
$$

Where $I_{\text {Integrated }}$ is nitrogen and phosphorus integrated index, $I_{P}$ is phosphorus and $I_{N}$ is nitrogen index. The nitrogen and phosphorus integrated index was ranked very low, low, medium, high and very high based on the variation in index values in the case study area.

\subsection{Agricultural Management Practices}

According to the calculation results of nitrogen and phosphorus integrated index, four different management options were applied and compared with the actual management in the catchment as follows [15]:

\subsubsection{Management Scheme 1: Base Fertilizer Applied deeply}

The premises for this option that all base fertilizer deeply application, in such fertilization approach, the level value recalculated after the update integrated risk index.

\subsubsection{Management Scheme 2: Construction of River Buff-} er Zone

The premises for this option included improving drainage conditions, mitigation of nitrogen and phosphorus losses and erosion risk by buffer zone construction.

\subsubsection{Management Scheme 3: Reduced Nitrogen Applica- tion}

The premises for this option comprised according to experts recommended amount of fertilizer, using one of the inputs of nitrogen fertilizer inputs for each crop management. Nitrogen input value changes, resulting in an initial nitrogen content index calculation grading changes.

\subsubsection{Management Scheme 4: Reduced Phosphorus Appli- cation}

The premises for this option are how to managing of phosphorus fertilization by using the value of the experts recommends.

\section{RESULTS AND ANALYSIS}

\subsection{Integrated Index of Phosphorus and Nitrogen}

The analysis of integrated index of phosphorus and nitrogen indicated that moderate or severe risk area accounted for $6.9 \%$ of the total area, mainly distributed in the central mountains at Dongzhuang catchment, these regions have a higher fertilizer inputs for the agricultural land, and the complex topography, soil erosion index was higher and in the rivers of the area (Fig. 2).

Further analysis showed that the areas where nitrogen is high but phosphorus index is not are mainly distributed in the central mountain; integrated risk index is higher in those areas. By contrast, phosphorus index is high but nitrogen index is not are mainly located in north-central, eastern and western of agricultural land, however, the overall risk of integrated index in these areas showed eastern and northern as low risk, while the middle west as high risk. Nitrogen and phosphorus index were lower in most areas of the basin, the regional distribution of these areas of integrated index to a few areas in northern ranked medium risk, other area as low risk. Nitrogen and phosphorus index in moderate area are mainly distributed in the northern and middle west of arable land and orchard, integrated risk index of these regions is mainly low risk for the northern, risk in southwest of medium and high risk in the middle west.

The results made above showed that the areas where nitrogen is high but phosphorus index is not, phosphorus index is high but nitrogen index is not and nitrogen and phosphorus index in moderate, there are some differences compared with nitrogen and phosphorus integrated index. Considered separately of nitrogen or phosphorus index are difficult to reflect the regional nitrogen and phosphorus losses, and it is easy to overlook the areas where nitrogen is high but phosphorus 


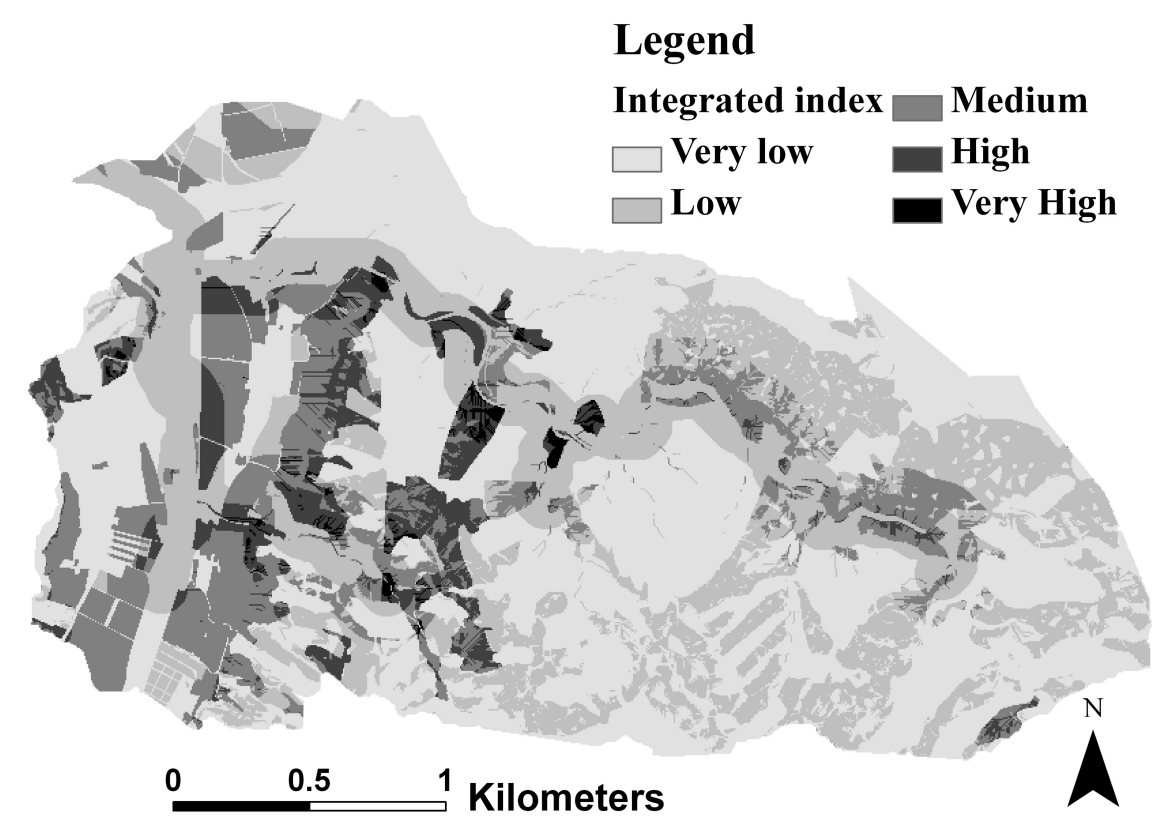

Fig. (2). Levels of Integrated Index at Dongzhuang Catchment.

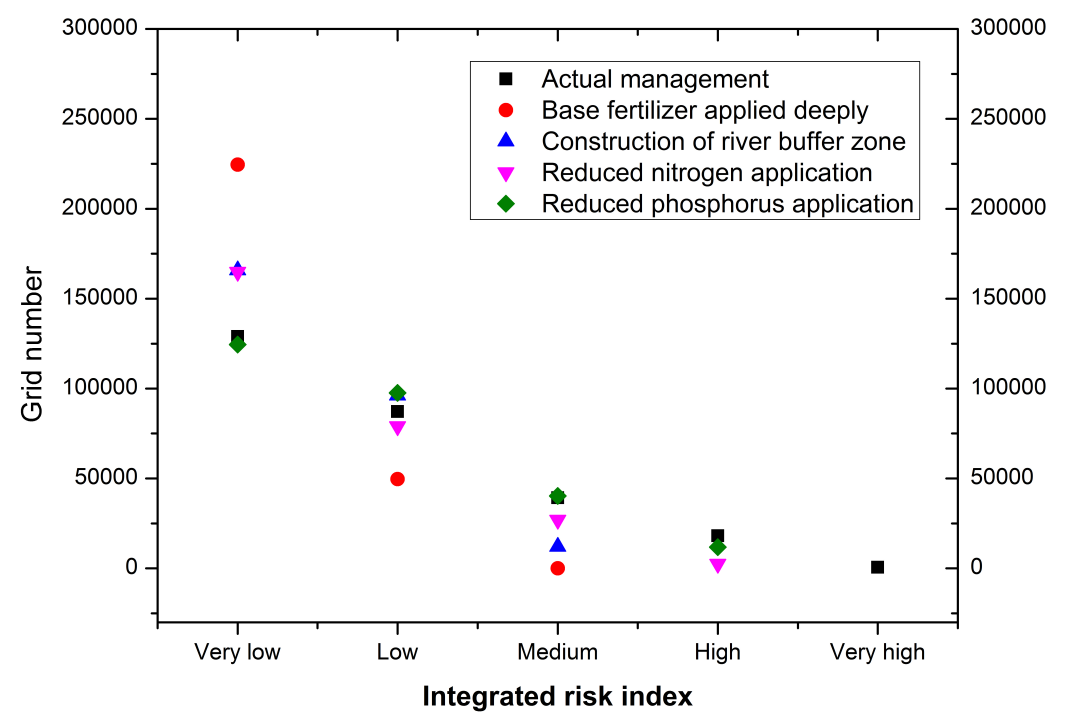

Fig. (3). Grid Number under Different Agricultural Management Practices.

index is not, phosphorus index is high but nitrogen index is not and nitrogen and phosphorus index in moderate, go against the comprehensive control measures of nitrogen and phosphorus losses risk.

\subsection{Grid Analysis under Different Agricultural Man- agement Practices}

The grid analysis shows that the different agricultural management practices lead to different risk index and number and proportion of grids are different, respectively. (Fig. 3, 4).

At very high risk area, about 599 of grid number is only for the actual management practice, accounting for $0.22 \%$ of the total, while at very low risk area, management measures have different quantity and the proportion of the grid, in which the grid number and proportion of river buffer zone scenario were 165884.00 and $60.51 \%$ respectively, although the reduced phosphorus application were 124521.00 and $45.42 \%$ respectively.

At high risk area, only actual management, reasonable nitrogen and phosphorus application has grid distribution, in which the grid number and proportion of actual management were 18138.00 and $6.62 \%$ respectively, while the reduced phosphorus application were 11780.00 and $4.3 \%$, and 2423.00 and $0.88 \%$ for reduced nitrogen application respectively. 


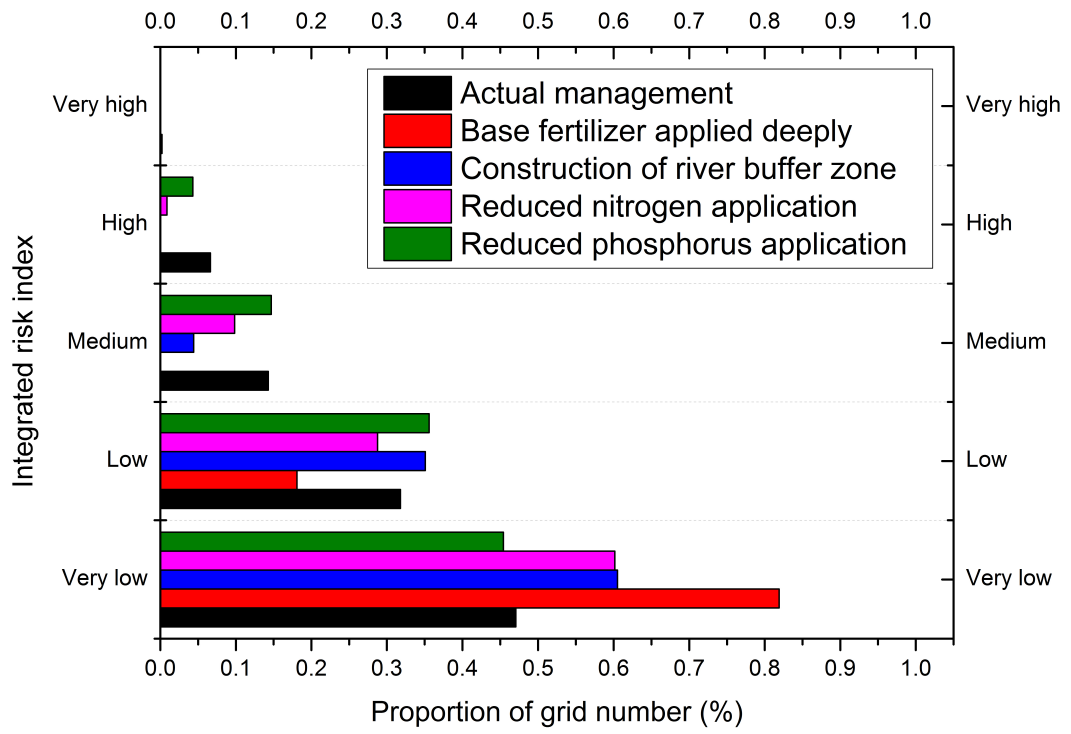

Fig. (4). Proportion of Grid Number under Different Agricultural Management Practices.

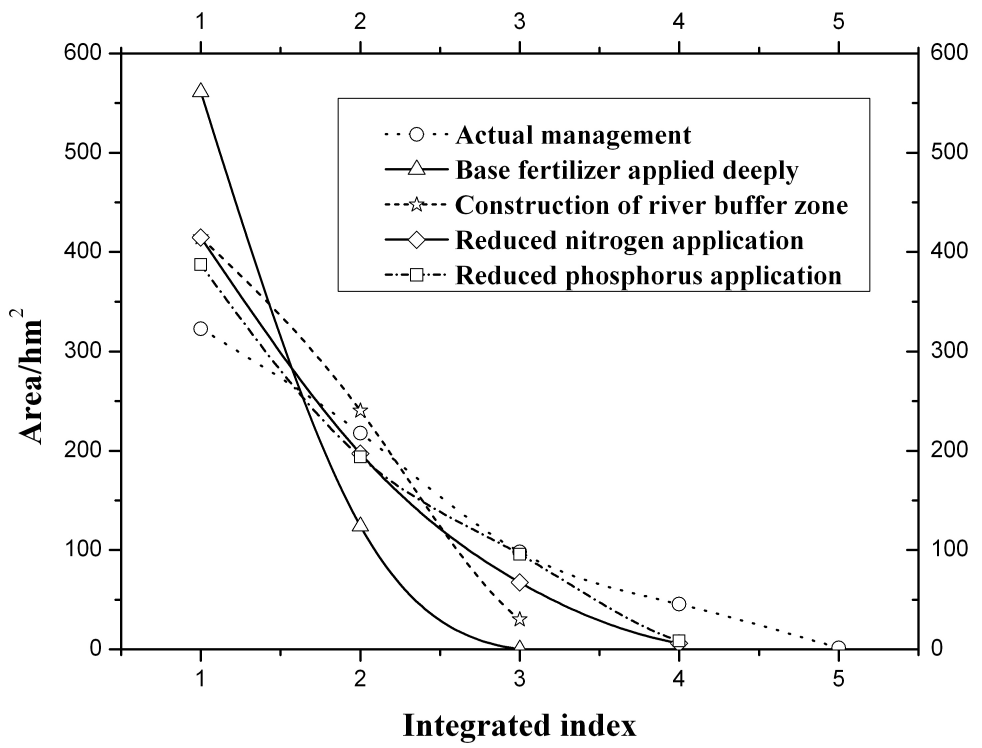

Fig. (5). The Area of Integrated Index Under Different Agricultural Management Practices.

By contrast, at the low-risk area, all management practices have a grid distribution. Among them, the number and proportion of the grid for actual management were 87157.00 and $31.79 \%$, respectively, 49605.00 and $18.10 \%$ for base fertilizer applied deeply respectively and 78875.00 and $28.77 \%$ for reduced nitrogen application respectively.

\subsection{Impacts of Agricultural Management Practices on the Risk of Nitrogen and Phosphorus Losses}

Compared with the present situation, the management scenario of integrated risk index range of sorting as follows: base fertilizer applied deeply> construction of river buffer zone $>$ reduced nitrogen application $>$ reduced phosphorus application (Fig. 5). Compared with actual management that very low and low risk areas accounted for $78.86 \%$ of total area, based fertilizer applied deeply scenario up to $98 \%$, and the buffer zone scenario was $95.6 \%$, while the reduced nitrogen and phosphorus application were $89.29 \%$ and $84.80 \%$.

\section{CONCLUSION}

In this paper, the integrated index models were used to evaluate risk of nitrogen and phosphorus losses at Dongzhuang catchment, northeast Beijing of China, explore impacts of agricultural management practices on the risk of nitrogen and phosphorus losses based on GIS and index models, so as to provide more reasonable reference for controlling strategy of nitrogen and phosphorus losses risk. 
The results indicated that grid analysis under different agricultural management practices showed that, the different agricultural management practices lead to different risk index and number and proportion of grids are different, respectively. Impacts of agricultural management practices on the risk of nitrogen and phosphorus losses indicated, compared with the present situation, the management scenario of integrated risk index range of sorting as follows: base fertilizer applied deeply $>$ construction of river buffer zone> reduced nitrogen application $>$ reduced phosphorus application.

Finally, the integrated index models were used to evaluate the control effect under different agricultural management practices, the results show different practices have different degrees of influence on risk of nitrogen and phosphorus losses. In which base fertilizer applied deeply is most effective for nitrogen and phosphorus losses controlling, while reduced phosphorus application has lower controlling effects.

\section{CONFLICT OF INTEREST}

The authors confirm that this article content has no conflicts of interest.

\section{ACKNOWLEDGEMENTS}

This research was supported by the National Natural Science Foundation of China (No.31300097), Scientific Research Program Funded by Shaanxi Provincial Education Department (2015), PhD research startup foundation of Xi'an Polytechnic University (BS1306) and students' innovation and entrepreneurship training foundation at the provincial level of Xi an Polytechnic University in 2014 (Project Number: 1234).

\section{REFERENCES}

[1] M. Bechmann, P. Stålnacke, S. Kværnø, H. O. Eggestad, and L. Øygarden, "Integrated tool for risk assessment in agricultural management of soil erosion and losses of phosphorus and nitrogen," Science of the total environment, vol.407, pp.749-759, 2009.
[2] G. Heckrath, M. Bechmann, P. Ekholm, B. Ulén, F. Djodjic, and H. E. Andersen, "Review of indexing tools for identifying high risk areas of phosphorus loss in Nordic catchments," Journal of Hydrology, vol.349,pp. 68-87, 2008.

[3] C. H. Bolster, P. A. Vadas, A. N. Sharpley, and J. A. Lory, "Using a phosphorus loss model to evaluate and improve phosphorus indices," Journal of Environmental Quality, vol.41, pp.1758-1766, 2012.

[4] R. Marjerison, H. Dahlke, Z. Easton, S. Seifert, and M. Walter, "A Phosphorus Index transport factor based on variable source area hydrology for New York State," Journal of Soil and Water Conservation, vol.66, pp. 149-157, 2011.

[5] B. P. Buchanan, J. A. Archibald, Z. M. Easton, S. B. Shaw, R. L. Schneider and M. T.Walter, " A phosphorus index that combines critical source areas and transport pathways using a travel time approach," Journal of Hydrology, vol.486, pp.123-135, 2013.

[6] Q. M. Ketterings, and K. J. Czymmek, "Phosphorus index as a phosphorus awareness tool: Documented phosphorus use reduction in New York State," Journal of Environmental Quality, vol.41, pp.1767-1773, 2012 .

[7] H. E. Andersen, and B. Kronvang, "Modifying and evaluating a $\mathrm{P}$ index for Denmark," Water, Air, and Soil Pollution, vol.174, pp.341-353, 2006

[8] J. M. D. Paz, J. A. Delgado, C. Ramos, M. J. Shaffer, and K. K. Barbarick, "Use of a new GIS nitrogen index assessment tool for evaluation of nitrate leaching across a Mediterranean region," Journal of Hydrology, vol.365, pp.183-194, 2009.

[9] U .Figueroa-Viramontes, J. A. Delgado, J. A. Cueto-Wong, G. Núñez-Hernández, D. G. Reta-Sánchez, and K. A. Barbarick, "A new Nitrogen Index to evaluate nitrogen losses in intensive forage systems in Mexico," Agriculture, ecosystems \& environment, vol.142, pp.352-364, 2011 .

[10] J. Drewry, L. Newham, and R. Greene, "Index models to evaluate the risk of phosphorus and nitrogen loss at catchment scales," Journal of Environmental Management, vol.92, pp.639-649, 2011.

[11] J. Delgado, M. Shaffer, C. Hu, R. Lavado, J. Cueto-Wong, P, Joosse, D. Sotomayor, W. Colon, R. Follett, and S. DelGrosso, "An index approach to assess nitrogen losses to the environment," Ecological engineering, vol.32, pp.108-120, 2008.

[12] X. Wang, and Q. Wang, "Loss of non-point source pollutants from Shixia small watershed, Miyun Reservoir, Beijing", Scientia Geographica Sinica, vol.24, pp.227-231, 2004.

[13] W. J. Gburek, and A. N. Sharpley, "Hydrologic controls on phosphorus loss from upland agricultural watersheds", Journal of Environmental Quality, vol. 27, pp.267-277, 1998.

[14] M. E. Bechmann, P. Stålnacke, S. H. Kværnø, "Testing the Norwegian phosphorus index at the field and subcatchment scale", Agriculture, ecosystems \& environment, vol.120, pp.117-128, 2007.

[15] F. Zhang, "Fertilizer application guide to China's main crop", China agricultural university press, 2009, Beijing.

This is an open access article licensed under the terms of the Creative Commons Attribution Non-Commercial License (http://creativecommons.org/licenses/bync/3.0/) which permits unrestricted, non-commercial use, distribution and reproduction in any medium, provided the work is properly cited. 